\title{
PÓS-GRADUAÇÃO EM METODOLOGIAS CONTEMPOR NEAS E TECNOLOGIAS: INOVAÇÃO EM FORMAÇÃO DOCENTE ATRAVÉS DO ENSINO HÍBRIDO
}

FORTALEZA/CE MAIO/2018

\author{
Ana Flávia Beviláqua Melo - FAE - flaviamelo_@hotmail.com \\ Andrea Chagas Alves de Almeida - FAE - andreachagasalmeida@gmail.com \\ Tipo: Relato de Experiência Inovadora (EI) \\ Categoria: Métodos e Tecnologias \\ Setor Educacional: EDUCAÇÃO SUPERIOR
}

\begin{abstract}
RESUMO
A importância da formação pedagógica para a prática profissional dos professores universitários é uma necessidade inerente dentro da docência e quando isso impacta na qualidade do ensino se vislumbra mudanças ainda mais necessárias. Nesse sentido, o trabalho em questão objetiva demonstrar a experiência da criação de uma formação docente por meio de uma Pós-Graduação aplicada e conduzida pelos professores da Faculdade de Tecnologia Evolução, que permitiu auxiliar na necessidade da formação pedagógica, se utilizando de estratégias metodológicas para a sua aplicação e fazendo uso do ensino híbrido como aliado na concretização da mesma. No estudo estão pautadas questões quanto à necessidade de como se fazer formação a professores do Ensino Superior em favorecimento ao aperfeiçoamento profissional e melhoramento da prática docente, além de apresentar apontamentos significativos quanto à oferta de formação para os saberes pedagógicos, metodológicos e tecnologias para o ensino e o posicionamento dos professores quanto a sua relevância e aplicabilidade.
\end{abstract}

Palavras-chave: Formação de professores. Docência universitária. Metodologias ativas. Ensino Híbrido. TDICS. 


\section{1 - INTRODUÇÃO}

A formação pedagógica do docente do Ensino Superior é uma questão que precisa ser discutida, além das políticas de formação inicial e continuada, como também da aquisição das competências para ensinar. Os professores que lecionam no Ensino Superior não possuem as bases pedagógicas para a docência, são selecionados pelos saberes de conteúdo e pela experiência de mercado e falta a exigência da formação para esse professor que complemente os saberes da prática docente. Segundo Vasconcellos (2009, p.86), "a graduação tem sido 'alimentada' por docentes titulados, porém, sem a menor competência pedagógica". Para a realização de um bom trabalho docente faz-se necessário que a prática esteja amparada nos quatro saberes.

Quanto ao primeiro saber, saberes da área de conhecimento, este é o único saber apontado pela a legislação como sendo obrigatório para a prática da docência universitária, conforme LDB 9394/1996. O segundo saber, saberes pedagógicos, as discussões sobre formação docente para a apropriação do conhecimento da prática pedagógica são mais recentes, tendo visto que somente a partir de 1990 é que se intensificaram os debates e as ações para a formação pedagógica na educação básica. Com a expansão do Ensino Superior intensificaram-se os debates quanto a necessidade da formação para a prática docente e os saberes pedagógicos.

O cenário atual mostra que as instituições de Ensino Superior possuem professores que concentram grande conhecimento de conteúdo técnico, porém não tem conhecimento das bases pedagógicas para transmitir esse conhecimento. Quanto a esses saberes, mesmo observando o que norteia a legislação sobre os quesitos mínimos para a entrada de um profissional na docência universitária, que no caso é ser portador de diploma no âmbito de uma área de conhecimento científico e ter Pós Graduação não, necessariamente, em educação ou em prática docente, há apontamentos que para se exercer a função de professor do Ensino Superior, seja necessário também os saberes pedagógicos.

O terceiro saber, os saberes didáticos, tratam-se das necessidades e possibilidades de aprendizagem do aluno. É através da atividade didática que se trabalha a ação e reflexão do aluno e que garantem a aprendizagem significativa. Nessa perspectiva entende-se que há necessidade do estudo e a apropriação da didática na formação do professor do Ensino Superior. Quanto ao quarto saber, os saberes da experiência do sujeito professor, apontam como ocorre o processo da apropriação do ser professor. Com a falta da formação da prática profissional para professores do Ensino Superior, estes por sua vez embasam suas práticas de ensino pautadas na experiência como alunos, filtrando dessas lembranças e vivências o que gostaram e o que não aprovaram 
na prática de ensino de seus ex-professores e aplicando o que e como estes fizeram. Esse processo de repetição não atende as demandas quanto ao processo de ensino e aprendizagem das demandas atuais.

Apesar de culturalmente se pregar que "quem sabe algo, sabe automaticamente ensinálo", como ressaltado por Masetto (2012), a verdade é que vivemos outros tempos onde a simples reprodução não basta. É importante que se entenda que a docência para o Ensino Superior não pode ser tratada apenas como um processo de transmissão de conteúdo. O conhecimento precisa ser construído amparado em habilidades e competências que somente os saberes de conteúdo não são suficientes para a execução dessa atividade tão complexa e assim se faz necessário a preparação desse professor para a prática profissional docente qualificada.

Nessa perspectiva, o trabalho apresentado é centrado na proposta de uma formação inicial e continuada para a prática profissional dos docentes da Faculdade de Tecnologia Evolução e as estratégias para desenvolvimento dessa formação. $O$ trabalho é de relevância, pois entende-se a necessidade de se avançar nas discussões quanto às questões da formação dos professores que ingressam na prática do Ensino Superior, promovendo sua qualificação e suas competências para ensinar nos tempos atuais diante de tantas possibilidade tecnológicas.

\section{2 - OBJETIVOS}

A proposta de trabalho objetiva demonstrar a necessidade da formação pedagógica e as estratégias utilizadas para a sua aplicação, pautadas questões quanto às novas metodologias para o ensino e o uso das tecnologias em apoio às essas metodologias. A formação docente foi proposta no formato de Pós Graduação em Metodologias Contemporâneas e Tecnologias para o Ensino, realizada através do ensino híbrido, na qual buscou trabalhar os desafios atuais de ensino-aprendizagem, promovendo ao professor, além da formação inicial, um aperfeiçoamento profissional junto a Faculdade de Tecnologia Evolução. Por meio desse relato de experiência, apresenta-se como a Pós Graduação trabalhou temas como a promoção de um grupo de estudo docente com tema pré estabelecido, a própria formação dos professores em Metodologias Ativas, o estímulo ao trabalho em pares, a indução ao autoaprendizado, a aplicação do conhecimento compartilhado, o fomento ao uso das tecnologias, a formação dos professores em nível Lato Sensu na área da Educação e o incentivo ao uso da Plataforma MOODLE, por meio do ensino híbrido.

\section{3 - REFERENCIAL TEÓRICO}

Um marco importante para a educação no Brasil nos últimos tempos foi a promulgação 
da LDB 9394/1996, porém diferente do anseio dos educadores quanto aos novos direcionamentos para a educação, as expectativas não foram correspondidas, incluindose também as questões quanto a formação e prática docente.

O artigo 66 da LDB de 9394/1996 traz que "a preparação para o exercício do magistério superior far-se-á em nível de pós-graduação, prioritariamente em programas de mestrado e doutorado", onde possibilita que qualquer graduado com pós-graduação poderá atuar no magistério de nível superior, sem qualquer formação para a prática docente e essa questão não foi revista ou reformulada desde então. O que se tem hoje são professores atuando no Ensino Superior sem preparação para a prática profissional docente, vários destes não tem a docência como profissão principal, sendo esta compartilhada a rotina de trabalho da formação específica deste profissional e as motivações são as mais variadas, sendo alguma destas a vocação, a experiência, a necessidade. Quanto ao perfil dos professores atuantes no Ensino Superior, temos:

(...) a) os profissionais de variadas áreas do conhecimento e que se dedicam à docência em tempo integral; b) os profissionais que atuam no mercado de trabalho específico e se dedicam ao magistério algumas horas por semana; c) os profissionais docentes da área pedagógica e das licenciaturas que atuam na universidade e, paralelamente, no ensino básico; d) os profissionais da área da educação e das licenciaturas que atuam em tempo integral nas universidades. (BEHRENS, 2008, p. 57).

Ainda em relação a essa heterogeneidade de identidade, Morosin (2000, p. 11) relata que:

Encontramos exercendo a docência universitária, professores com formação didática obtida em cursos de licenciatura; outros, que trazem sua experiência profissional para a sala de aula; e, outros ainda, sem experiência profissional ou didática, oriundos de curso de especialização e/ou stricto sensu.

Esse perfil se difere também quando analisamos os professores das IES públicas e privadas. É possível perceber que os professores com maior titulação se encontram nas instituições públicas, isso é esperado uma vez que os professores dessas instituições passam por concurso público e acabam por seguir a carreira docente e a própria característica formativa das IES públicas que tem a pesquisa associada ao ensino que acaba por fomentar o aperfeiçoamento profissional do professor. É importante ressaltar que o fato de se ter um quadro de professores de alta titulação, não necessariamente mostra que esse professor tem formação para a docência e sim que esse professor tem formação mais específica.

Em paralelo a essa realidade das titulações docentes, vê-se que as instituições de ensino estão a cada dia mais exigentes em relação às formações docentes e ao uso de tecnologia, visto a era em que estamos vivendo e às exigência do perfil dos alunos 
egresso das IES. Nos tempos atuais os desafios do processo de ensino e aprendizagem são maiores, pois há questões que vão além do ensinar e aprender e de formar o aluno para uma profissão, que por si só já é uma missão bem complexa. Há uma necessidade da formação de conhecimento de mundo e valores sociais, aliados a sociedade que vivemos hoje na era da informação on-line, que além dessas informações e conteúdos chegarem ao aluno na velocidade de um clique não precisam ser retidas uma vez que a reconsulta é tão, ou mais, rápida quanto a consulta. É nesse aspecto, das novas formas de aprender do aluno, que os professores precisam se apropriar e para isso se faz necessário o estudo e o amparo a prática profissional.

Nessa perspectiva, repensar a prática docente para o ensino superior requer um diferencial metodológico, que pode ser vivenciado pelo professor durante a formação continuada. Percebe-se o déficit que ainda tem nos docentes em relação às formações pedagógicas e didáticas, principalmente se for relacionando essa formação a tecnologia. A maioria dos professores é bem treinada em conteúdo e possui uma compreensão profunda das áreas em que está ensinando, no entanto, muitas vezes esse docente é confrontado com o enorme desafio das mudanças, principalmente tecnológicas, bem como a falta da base pedagógica, da didática e da experiência no desenvolvimento de competências. "Para ser professor hoje, não se permite apenas o ensino de conteúdos, faz-se necessário que o professor se utilize de diferentes mecanismos para motivar e engajar os seus estudantes no processo educativo [...]" (VASSOLER; AFONSO, 2017, p. 233).

Assim, entendendo o perfil dos professores que compõem o corpo docente da Faculdade Evolução, que é formado em sua maioria por profissionais do mercado de trabalho, e por ser uma IES que possui exclusivamente turmas noturnas, o que se propôs foi uma formação no formato híbrido, sendo a maior parte amparada na Educação a Distância, para que fosse viável o processo de formação uma vez que se pensou em um processo de estudo constante para os docentes da Faculdade Evolução. A formação através da EAD permite diminuir as lacunas espaço $x$ tempo; otimizar os momentos livres, pois não se precisa fazer, por exemplo, um deslocamento para estudar; manter a constância nos estudos, uma vez que é indiferente se há feriado, fim de semana ou recesso; possibilita o fomento ao uso das tecnologias, pois hoje não se pensa EAD sem o uso de tecnologias, como plataforma de aprendizado, redes sociais e recursos interativos. Neste sentido, este artigo objetiva apresentar a trajetória da formação docente por meio de uma pós-graduação de metodologias e tecnologias contemporâneas, no modelo híbrido, com professores da Faculdade Evolução, como base metodológica a utilização das metodologias ativas. 


\section{4 - PROCEDIMENTOS METODOLÓGICOS}

A formação docente teve sua idealização estruturada sob uma ótica das novas dimensões de mercado, ou seja, pensou-se na necessidade de formação docente nas práticas metodológicas atuais, bem como no envolvimento institucional com a tecnologia e consequentemente com a melhoria no processo de ensino-aprendizagem. É importante salientar, que essa necessidade surgiu a partir do vislumbre das mudanças estruturais que a educação vem passando, desde concepções metodológicas à reorganização de oferta nos modelos EaD, presencial e híbrido como o perfil dos estudantes presentes no Ensino Superior.

Assim, o curso teve como nome Pós Graduação em Metodologias Contemporâneas e Tecnologias para o Ensino, no modelo híbrido (8h de atividades presenciais e 24h de atividades online), com duração de 12 meses e carga horária de 432h, tendo 352h de disciplinas obrigatórias (totalizando 11 disciplinas) e o Trabalho de Conclusão de Curso com 80h. O curso teve seu início em setembro de 2017 e previsão de finalização em julho de 2018 e apresentação do artigo em agosto de 2018.

Cada disciplina ofertada tinha duração de 1 mês, ocorrendo essencialmente na plataforma Moodle, e tendo 1 encontro presencial em horário integral. O conteúdo passado era desenvolvido e apresentado por docentes que trabalhavam em pares, bem como atuavam com papéis diferentes em momentos diversos, ou seja, a cada nova disciplina hora eles eram docentes das disciplinas, ora eles eram alunos da disciplina. Isso permitiu aos docentes uma maior familiarização com as tecnologias, bem como o ensino híbrido, a plataforma Moodle e a ferramenta de WhatsApp, ainda tão pouco utilizada pelos mesmos, e que era um dos pilares da formação. Nesse olhar, Morán $(2015$, p.16) reforça esse pensamento quando fala que:

\footnotetext{
O que a tecnologia traz hoje é integração de todos os espaços e tempos. O ensinar e aprender acontece numa interligação simbiótica, profunda, constante entre o que chamamos mundo físico e mundo digital. Não são dois mundos ou espaços, mas um espaço estendido, uma sala de aula ampliada, que se mescla, hibridiza constantemente. Por isso a educação formal é cada vez mais blended, misturada, híbrida, porque não acontece só no espaço físico da sala de aula, mas nos múltiplos espaços do cotidiano, que incluem os digitais.
}

Nessa perspectiva, a ideia inicial do projeto foi ofertar inicialmente a Pós Graduação no modelo híbrido, apenas aos docentes da instituição, numa oportunidade de formação formal, compreendendo o significado de aprendizagem, experiências inovadoras, práticas exitosas, além de contar com certificação e produção científica.

Na Reunião Acadêmica do final do semestre 2017.1 foi apresentado aos professores da Graduação da Faculdade Evolução a proposta do grupo de estudo com tema no eixo 
novas metodologias e foi feito o convite para a participação. Em agosto de 2017 os professores fizeram sua inscrição, bem como escolheram os temas que se identificaram mais e que entendiam que era possível de ser estudada e ministrada por ele. Sendo a formação um convite e não uma imposição inerente a função, houve o aceite de mais de $70 \%$ do corpo docente em participar, tendo no decorrer do curso de formação a desistência de apenas 1 (um) professor.

Com base na necessidade de se gerar competências pedagógicas para o ensino e aproximar os professores das tecnologias, os conteúdos e suas pré ementas foram criadas e socializadas entre os professores e ficaram estruturadas da seguinte maneira:

- Plataforma MOODLE, com oficina e uso da ferramenta;

- História e Concepção das Metodologias Ativas (MA), conceituando o que são e quais os tipos de MA, bem como problematizações acerca do uso das MA's;

- Neurociência, trazendo as formas de aprender, benefícios para a educação e seus recursos;

- Métodos e Técnicas de Ensino, buscando elucidar a conceituação, métodos de didática de sala de aula e estratégias do trabalho docente;

- Pedagogia dos Projetos, também com conceituação, projetos como método de ensino e execução de projeto;

- Flipped Classroom - A sala de aula invertida, trazendo a história e a aplicabilidade de como fazer a sala de aula invertida, bem como trazendo uma mudança de metodologia na sua aplicação, com uso das TDIC's e outras formas de apoio;

- Laboratório de Aulas Criativas, com a definição de criatividade, apresentação de espaços de ensino diferenciado, uso de material concreto e lúdico e novas formas de apresentar o conteúdo proposto;

- TDIC's (Tecnologias Digitais de Informação e Comunicação), conceituando e apresentando ferramentas tecnológicas de apoio no processo de ensino e aprendizagem e aplicação de recursos em nível avançado da Plataforma MOODLE e gamificação de conteúdo;

- Pesquisa como Princípio Educativo, trabalhando fundamentos, tipos e princípios da pesquisa, bem como aplicação e fomento a iniciação a pesquisa;

- Processos e Métodos Avaliativos, com princípio conceitual e aplicação nas formas de avaliação, múltiplas inteligências, novas metodologias versus nova forma de avaliar e avaliação diversificada.

É importante ressaltar que as escolhas das disciplinas e a forma como ambas foram trabalhadas e conduzidas têm relação com o objetivo inicial do projeto, que leva o nome de "Metodologias Contemporâneas e Tecnologias para o Ensino", e buscou 
constantemente motivar o participante, ora professor, ora aluno, que por diversas vezes tinha que explorar e criar possibilidades. E todas essas possibilidades apresentadas poderiam ser revertidas em atividades avaliativas, bem como experiências inovadoras e práticas exitosas para poderiam ser utilizadas com os alunos nas disciplinas ofertadas no semestre corrente. Nesse sentido além da busca pelo aprendizado em si, buscou-se principalmente o envolvimento do professor neste processo, fosse ora aluno, ora professor.

\section{5 - RESULTADOS}

A proposta da pós-graduação, ofertada como experimentação, acredita-se que já tem experiências exitosas, além de ter possibilitado até o momento uma série de observações, de cunho qualitativo, mas que atende inicialmente a proposta da formação, que é o aumento do número de professores/disciplinas que utilizam o MOODLE; uma melhora na avaliação docente, feita pelo aluno; o relato dos professores; a mudança na dinâmica das aulas e nos processos avaliativos e a melhora na relação professor $x$ aluno, pois esse processo de formação docente propiciou ainda maior empatia dos professores com seus alunos uma vez que o formato da formação os colocou em condição de aluno. É possível também perceber como a estrutura da Educação a Distância pode ser bem trabalhada, apesar de ser trabalhosa. Para que o curso funcionasse nesse sistema híbrido foi necessário primeiramente vencer o bloqueio do espaço virtual e de entender que mesmo em espaços de trabalho atemporais é importante a organização do tempo e o comprometimento com o trabalho proposto. Vencido a barreira inicial e com a apropriação do espaço virtual de aprendizagem o processo tendeu não só a uma fluidez maior, como também a uma robustez das atividades e interações.

Em contrapartida, tiveram alguns desafios, entre eles envolver o professor no processo de formação, bem como no processo de construção do conteúdo referente a disciplina que iria ministrar, tirando-o da zona de conforto e do olhar tradicional do ensinoaprendizagem, envolvendo-o nas possibilidades do EAD, nas metodologias ativas e nas diversas técnicas existentes. No entanto, o envolvimento do professor foi sendo conquistado a cada nova disciplina e a cada nova possibilidade que se apresentava, e a participação dele foi sendo observada a cada nova interação fosse pelo Moodle, ou pelo próprio WhatsApp, ou através dos recursos disponibilizados como canal de comunicação e estudo.

A proposta da formação não só rendeu uma melhora na qualidade das aulas, como despertou no professor o entendimento da necessidade da formação. Os professores pertencentes ao corpo docente em formação estão abertos a continuidade da formação 
pedagógica que é uma das maiores vitórias deste processo. Os professores se enxergam como profissionais da educação e como todo profissional precisa se aperfeiçoar, se atualizar. Além disso, a estrutura da formação ter sido no formado de ensino híbrido, facilitou não só a adesão dos professores, mas favoreceu a permanência destes na formação e permitiu ainda a continuidade dos trabalhos de forma ininterrupta durante todo o período.

\section{6 - CONSIDERAÇÕES FINAIS}

A importância da formação de professores para a prática da docência no Ensino Superior se confirma através dos resultados satisfatórios nas avaliações docentes feitas pelos alunos sobre seus professores; nos discursos dos docentes pertencentes ao corpo em formação que percebem melhora no desenvolvimento de suas aulas, bem como a aplicabilidade dos recursos aprendidos na formação; do notório avanço no uso das TDIC por parte dos professores e em consequência por parte dos alunos para fins de aprendizagem; da apropriação dos professos na Plataforma MOODLE e suas possibilidades de trabalho como aporte a materiais de estudo, interação do aluno com o professor e com o conteúdo disponibilizado e realização de atividades avaliativas.

Seria ousadia demasiada revelar que não se percebe mais nenhuma resistência vindo dos professores em relação a plataforma MOODLE e/ou a modalidade EAD e/ou ensino híbrido, porém é possível afirmar que muitas mudanças comportamentais foram notadas a partir do momento que os professores entenderam que para melhorar sua atuação docente é preciso pensar em novas estratégias e metodologias, bem como permitir mais autonomia e auto estudo do aluno, moderando um processo de ensino-aprendizagem em que o aluno se torna protagonista da situação e o professor orientador do aluno. Acredita-se assim, que o trabalho realizado para a formação de professores da Faculdade Evolução já é tangível e possível de desdobramentos não só para outras formações em temas diferentes, mas como para outros tipos de formação.

\section{REFERÊNCIAS BIBLIOGRÁFICAS}

BEHRENS, Maria Aparecida. A formação pedagógica e os desafios do mundo moderno. In: MASETTO, Marcos (Org.). Docência na Universidade. 9. ed. Campinas: Papirus, 2008, p. 57-68

BRASIL. INEP. Censo Escolar da Educação Superior 2016. Brasília, DF: Ministério da Educação/Instituto Nacional de Estudos e Pesquisas Educacionais Anísio Teixeira, 2010. Disponível em: Disponível em: Acesso em: 03 maio 2018.

BRASIL. Ministério da Educação. Lei no 9394 de 20 de dezembro de 1996. Lei de Diretrizes e Bases da Educação Nacional. Brasília - FD: Casa Civil, 1996.

MASETTO, M. T. Competência pedagógica do professor universitário. 2. ed. 
revisada. São Paulo: Summus, 2012.

MORÁN, José. Mudando a educação com metodologias ativas. In: SOUZA, Carlos Alberto de; MORALES, Ofelia Elisa Torres (orgs.). Coleção Mídias Contemporâneas. Convergências Midiáticas, Educação e Cidadania: aproximações jovens. Vol. II. PG: Foca Foto-PROEX/UEPG, 2015. Disponível em: . Acesso em: 03 maio 2018.

MOROSIN, Marília. Docência universitária e os desafios da realidade nacional. Instituto Nacional de Estudos e Pesquisas Educacionais, Brasília: Instituto Nacional de Estudos e Pesquisas Educacionais, n.2, p.11-21, 2000.

TARDIF, Maurice. Saberes docentes e formação profissional. Petrópolis, RJ: Vozes, 2002.

VASCONCELOS, Maura Maria Morita. Contribuindo para a formação de professores universitários: relatos de experiências. In: Masetto, Marcos Tarciso (Org.). Docência universitária. 10. ed. Campinas: Papirus, 2009. p.77-94.

VASSOLER, Karina Lucia de Freitas; AFONSO, Germano Bruno. Formação de professores de educação em tempo integral. In: ALMEIDA, Siderly do Carmo Dahle de; MEDEIROS, Luciano Frontino de; MATTAR, João (Org.). Educação e Tecnologias: Refletindo e transformando o cotidiano. São Paulo: Artesanato Educacional, 2017, p. 222-245. 